\title{
Associations Between Headache-Free Days and Patient-Reported Outcomes Among Migraine Patients: A Cross-Sectional Analysis of Survey Data in Europe
}

\author{
Michael J. Doane $\cdot$ Shaloo Gupta (D) - Pamela Vo · Annik K. Laflamme • \\ Juanzhi Fang
}

Received: April 30, 2019 / Published online: July 26, 2019

(c) The Author(s) 2019

\section{ABSTRACT}

Introduction: Migraine imposes a substantial burden on patients, society, and healthcare systems. This study aimed to assess the associations between the number of headache-free days (HFDs) and health-related quality of life (HRQoL), work productivity and activity impairment (WPAI), and healthcare resource utilization (HRU) in patients with migraine in the EU5 (France, Germany, Italy, Spain, and the United Kingdom).

Methods: This retrospective cross-sectional study collected survey responses from adults aged $\geq 18$ years from the 2017 National Health and Wellness Survey $(N=62,000)$. Migraine patients with a physician's diagnosis of migraine and who had experienced at least 4 monthly headache days in the prior month were included $(N=1569)$. Number of HFDs was

Enhanced Digital Features To view enhanced digital features for this article go to: https://doi.org/10.6084/ m9.figshare.8907326.

M. J. Doane · S. Gupta $(\bowtie)$

Kantar Health, New York, NY 10010, USA

e-mail: shaloo.gupta@kantarhealth.com

P. Vo · A. K. Laflamme

Novartis Pharma AG, Fabrikstr. 12, 4002 Basel, Switzerland

J. Fang

Novartis Pharmaceuticals Corporation, One Health

Plaza, East Hanover, NJ 07936, USA compared with Short-Form 12-Item Survey Instrument, version 2 (SF-12v2) physical and mental component summary scores (PCS and MCS), Short-Form-6D (SF-6D) and EuroQoL-5D (EQ-5D) scores, WPAI, and HRU in migraine patients. Correlation analyses were conducted to test the bivariate associations, whereas generalized linear models were used for multivariable analyses.

Results: An increase of $1 \mathrm{HFD}$ was associated with average increases of $0.171,0.306,0.003$, and 0.008 points for MCS, PCS, SF-6D utility score, and EQ-5D index score, respectively $(p<0.001$ for all). Extrapolating the results to a tenfold increase in monthly HFDs corresponded to clinically meaningful increases in PCS and EQ-5D scores. An increase of 1 HFD was associated with expected average decreases in absenteeism of $3.9 \%$ and presenteeism of $2.1 \%$. Further, an increase of 1 HFD was associated with expected decreases in HCP visits and neurologist visits of $1.0 \%$ and $4.7 \%$, respectively.

Conclusion: An increase in the number of HFDs was associated with better health-related outcomes in patients suffering from migraine. Further, the results demonstrate a need for more effective treatments that can reduce migraine frequency and thus improve HRQoL, increase work productivity, and reduce both activity impairment and HRU.

Funding: Novartis Pharma AG, Switzerland. 
Keywords: Activity impairment; Burden; Headache-free days; Healthcare resource use; Health-related quality of life; Migraine; Work impairment

\section{INTRODUCTION}

Headache disorders, one of the most common nervous system disorders characterized by recurrent headache, are broadly classified into primary and secondary headache disorders [1]. Primary headache disorders include migraines, tension-type headaches, and cluster headaches [2]. Secondary headache disorders include headaches attributed to: (1) trauma or injury to the head and/or neck, (2) cranial and/or cervical vascular disorder, (3) nonvascular intracranial disorder, (4) a substance or its withdrawal, (5) infection, (6) disorder of homeostasis, and (7) psychiatric disorder [3].

Migraine is a common neurological disorder that can be disabling, and is the most common form of primary headache disorder. The two major types of migraine are migraine with aura and migraine without aura. Based on the headache frequency, migraine can be divided into episodic migraine (headaches for $<15$ days/ month) and chronic migraine (headaches for $\geq 15$ days/month for $>3$ months) [3].

Per the Global Burden of Disease Study 2016, migraine affects nearly 1.04 billion people globally [4]. A recent study by Woldeamanuel et al. reported the prevalence of migraine at $11.6 \%$ globally and $11.4 \%$ in Europe [5]. Migraine is the second leading cause of years lived with disability (YLDs) in 2016, contributing 45.1 million YLDs globally [4]. Migraine is 2-3 times more common among women than men [6]. Furthermore, the prevalence of migraine is highest during the prime years of productivity, i.e., 30-39 years [7].

Previous studies have clearly established that migraine is associated with a decreased healthrelated quality of life (HRQoL) [8, 9]. Migraine also impacts the functional capacity of individuals, disrupting work and social activities [10]. In addition, migraine imposes an economic burden on both individuals and society $[11,12]$.
The increased frequency of headaches experienced by migraineurs has an additional impact on HRQoL, work productivity and activity impairment (WPAI), healthcare resource utilization (HRU), and associated costs [13-15]. Chronic migraine is more disabling than episodic migraine and is associated with greater impairment of HRQoL in addition to greater societal burden [12]. A recent study by Vo et al. in the EU5 (i.e., France, Germany, Italy, Spain, and the United Kingdom) demonstrated that migraine patients experiencing $\geq 4$ monthly headache days (MHDs) experienced incremental burdens in HRQoL, WPAI, and HRU [16].

Further, patients with episodic migraine can progress to episodic high-frequency or chronic migraine over time if treatment is not effective. Hence, treating episodic migraine patients with lifestyle management and prophylaxis and selecting and initiating the most appropriate treatment strategy can reduce pain, frequency, and severity of headache days $[17,18]$.

Globally, there is a need to understand the relationship between the number of headachefree days (HFDs) and the aforementioned parameters to reduce the burden of migraine patients, particularly of those suffering from the chronic form. However, there is a paucity of data on the associations of the number of HFDs with various patient-reported outcomes in migraine patients [19].

The objective of this study was therefore to assess the associations between the number of HFDs and various patient-reported outcomes (HRQoL, WPAI, and HRU) in patients suffering from migraine in the EU5.

\section{METHODS}

\section{Sample}

This retrospective cross-sectional study collected survey responses from adults aged 18 years or older from the 2017 National Health and Wellness Survey (NHWS; $N=62,000$ ) in the EU5. All respondents consented to participate in the survey and could read and write in the primary language of their country of residence (i.e., French, German, Italian, Spanish, and 
English for France, Germany, Italy, Spain, and the UK, respectively) at the time of the survey.

Potential respondents to this survey were members of MySurvey.com or its partners, which are opt-in survey panels. Recruitment of respondents was through opt-in e-mail, co-registration with MySurvey.com partners, e-newsletter campaigns, banner placements, and both internal and external affiliate networks. For respondents from countries with insufficient internet penetration among the elderly (i.e., Spain and Italy), telephone recruitment using quota sampling based on age and gender supplemented the online recruitment to provide an adequate sample of the elderly population. For those without internet access, a computer in a private center was provided to complete the survey. All respondents provided informed consent. All potential panelists for this survey registered with the panel through a unique e-mail address and password and completed an in-depth demographic registration profile. The protocol and questionnaire for the NHWS were reviewed by the Pearl Institutional Review Board and found to be exempt from review for the current study. All NHWS respondents provided informed consent prior to their participation.

From this general survey, migraine patients were defined as those who (1) reported a doctor's diagnosis of migraine, (2) experienced at least 1 migraine during the prior month, and (3) experienced at least 4 headache days during the prior month.

\section{Measures}

\section{Sociodemographic Characteristics}

Measures included gender, country of residence (i.e., France, Germany, Italy, Spain, and the UK), age, employment status (employed vs. unemployed), annual household income (low vs. medium vs. high vs. declined to answer), marital status (married or living with partner vs. single/divorced/widowed), level of education (completed university education vs. not completed university education), and labor force participation (currently in the labor force vs. not currently in the labor force).

\section{General Health Characteristics}

General health characteristics included body mass index (BMI) calculated from self-reported height and weight and categorized as underweight $\left(<18.5 \mathrm{~kg} / \mathrm{m}^{2}\right)$, normal weight $(18.5$ to $\left.<25.0 \mathrm{~kg} / \mathrm{m}^{2}\right)$, overweight $(25.0$ to $<30.0$ $\left.\mathrm{kg} / \mathrm{m}^{2}\right)$, obese $\left(\geq 30.0 \mathrm{~kg} / \mathrm{m}^{2}\right)$, or declined to answer. Other characteristics included cigarette smoking (current vs. former vs. nonsmokers), frequency of alcohol use (daily vs. less than daily vs. none), days of exercise in the past 30 days, and the Charlson Comorbidity Index (CCI) [20]. CCI weights the presence of the various conditions according to their severity and then sums the result; those conditions are human immunodeficiency virus infection/acquired immune deficiency syndrome (HIV/ AIDS), metastatic tumor, lymphoma, leukemia, any tumor, moderate/severe renal disease, hemiplegia, diabetes, mild liver disease, ulcer disease, connective tissue disease, chronic pulmonary disease, dementia, cerebrovascular disease, peripheral vascular disease, myocardial infarction, congestive heart failure, and diabetes with end-organ damage. The greater the total index score, the greater the comorbid burden on the patient.

\section{Health-Related Quality of Life}

$\boldsymbol{S F - 1 2 v 2}$ The 2017 NHWS included the standard 4-week recall period of the revised Medical Outcomes Study 12-Item Short-Form Survey Instrument, version 2 (SF-12v2), which is a multipurpose, generic health status instrument comprising 12 questions [21] that are designed to report on 8 health concepts (i.e., physical functioning, role physical, bodily pain, general health, vitality, social functioning, role emotional, and mental health). Physical component summary (PCS) and mental component summary (MCS) scores were calculated from the SF$12 \mathrm{v} 2$. Higher scores indicate a better quality of life (QoL).

In addition to generating profile and summary PCS and MCS scores, the SF-12v2 can also be used to generate health state utilities. This is achieved through application of the Short-Form Six-Dimension (SF-6D), which takes 6 items from the survey. The SF-6D is a preference-based single index measure for health using the values 
for the UK general population [22]. The SF-6D index has interval scoring properties and yields summary scores on a theoretical 0-1 scale. Higher scores indicate a better QoL.

\section{EQ-5D-5L index score}

The EuroQoL-5D (EQ-5D) index score is a preference-based measure of health on a theoretical scale of $0-1$ with 1 equal to full health and 0 being equal (in terms of preference) to death. It is derived from responses to the EQ-5D-5L, a widely used survey instrument that measures health in five dimensions. The most recent version with a 5-point rating scale for each dimension was included in the questionnaire for this study [23]. The index score for the UK was calculated per the standard value set for the UK, and the index values for France, Germany, Italy, and Spain were calculated using the crosswalk from the EQ-5D$3 \mathrm{~L}$, as the value set for the $5 \mathrm{~L}$ version has not been published yet. The EQ-5D-5L also provided additional measures of HRQoL beyond the index. This included the visual analog scale (VAS) [23], which is a single item that allows the respondents to rate their health from 0 to 100 , with 0 representing the worst possible health state and 100 representing the best possible health state.

\section{Work Productivity and Activity Impairment}

Work productivity impairment was assessed using the General Health version of the Work Productivity and Activity Impairment (WPAI$\mathrm{GH})$ questionnaire [24], a 6-item validated instrument that consists of 4 metrics: absenteeism (the percentage of work time missed because of one's health in the past 7 days), presenteeism (the percentage of impairment experienced while at work in the past 7 days because of one's health), overall work productivity loss (an overall impairment estimate that is a combination of absenteeism and presenteeism), and activity impairment (the percentage of impairment in daily activities because of one's health in the past 7 days).

Only respondents who reported being fulltime, part-time, or self-employed provided data for absenteeism, presenteeism, and overall work impairment. All respondents completed the activity impairment questionnaire.

\section{Healthcare Resource Utilization}

Healthcare use was defined by visits to different medical providers during the prior 6 months. For traditional healthcare providers (HCPs), such as physicians and nurses, the visits were summarized and analyzed for each type of provider in the prior 6 months as well as the number of visits during that time. Reported data included overall visits to a HCP, primary care provider, neurologist, psychiatrist, psychologist, emergency room (ER), and hospitalization in the past 6 months.

\section{Statistical Methods}

All data management and analyses were performed in SPSS 23.0 and/or SAS 9.4. The overall sample was characterized based on the variables using descriptive statistics, including frequencies and percentages for categorical variables and means and standard deviations for continuous variables. Correlation analyses were conducted to test the bivariate associations between the number of HFDs and various outcomes using Pearson and Spearman correlation tests to examine parametric and nonparametric associations, respectively. Demographic and health characteristics that were found to significantly correlate with the number of HFDs were included as covariates in the multivariable analysis.

For multivariable analyses, generalized linear models (GLMs) were used to estimate the associations of the number of HFDs with various health outcomes after controlling for covariates. GLMs specifying a normal distribution and identity function were used with normally distributed outcomes (such as HRQoL) [25], whereas GLMs specifying a negative binomial distribution and log-link function were used for count data (e.g., WPAI [26] and HRU [27]).

The rate ratio (RR) was calculated as follows: If $\mathrm{RR}$ is $<1$, a 1-unit (i.e., 1-day) increase in the number of HFDs is associated with a $(1-\mathrm{RR}) \times 100 \%$ decrease in the outcome. If RR is $>1$, a 1-unit (i.e., 1-day) increase in the number of HFDs is associated with a $(1+\mathrm{RR}) \times 100 \%$ increase in the outcome. 


\section{RESULTS}

Of the 62,000 respondents in total, approximately 13,063 indicated experiencing migraine, and 6181 respondents indicated a physician's diagnosis of migraine, completed the migraine module, and provided the frequency of migraines. Out of these 6181 respondents, 4612 either reported that they had not experienced any migraines in the past month or they did not know the number of MHDs experienced in the prior month or they provided a migraine frequency corresponding to rare migraine $(\leq 3$ MHDs); those respondents were excluded from this study. Migraine patients who had a physician's diagnosis of migraine and had experienced at least 4 MHDs in the prior month were included in this analysis $(N=1569)$. The number of HFDs in migraine patients was defined as: 30 days - number of headache days in the past 30 days (Fig. 1).

The demographic characteristics of respondents diagnosed with migraine who reported HFDs are presented in Table 1. Among the respondents diagnosed with migraine, $21.9 \%$ were from France, $26.1 \%$ from Germany, 23.9\% from the UK, $20.0 \%$ from Italy, and $8.1 \%$ from Spain. Additionally, $77.8 \%$ of them were female and had a mean age of 43.27 years, $60.7 \%$ were married or living with a partner, and $27.9 \%$, $36.8 \%$, and $28.9 \%$ belonged to the low-,

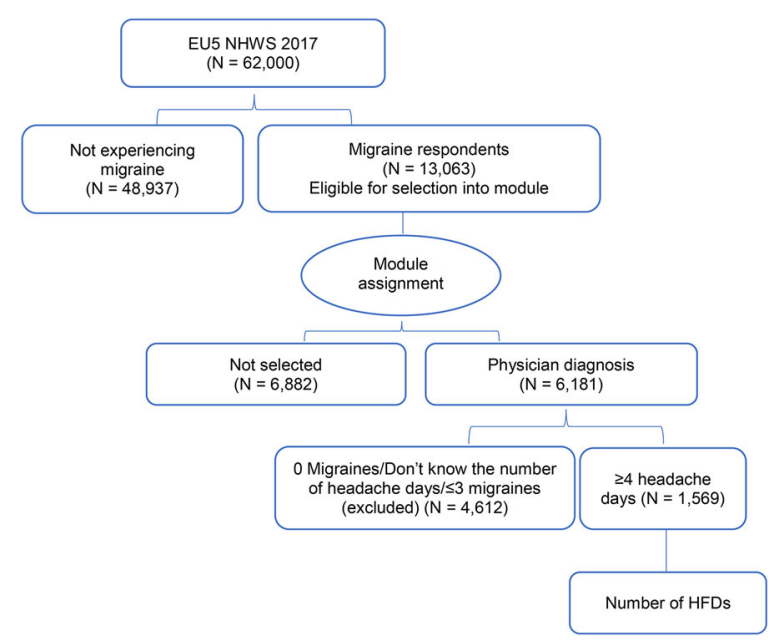

Fig. 1 Selection of the study population. HFDs headachefree days, NHWS National Health and Wellness Survey medium-, and high-income groups, respectively. Furthermore, 36.8\% completed a university education, and 59.8\% reported being currently employed. Based on health characteristics, $48.8 \%$ were overweight or obese, $29.7 \%$ were smokers, $71.8 \%$ drank alcohol, and $60.2 \%$ mentioned that they have done some sort of exercise in the past 30 days.

The mean MCS, PCS, SF-6D, and EQ-5D scores of migraine patients who reported HFDs were $39.73,46.61,0.62$, and 0.71 , respectively. Among employed respondents, mean absenteeism, presenteeism, and total work productivity impairment were $13.39,34.70$, and 37.73 , respectively. The mean activity impairment in the migraine respondents was 43.31. Among migraine respondents who reported HFDs, the mean number of HCP visits in the past 6 months was 8.38 , the mean number of hospitalizations was 0.22 , the mean number of ER visits was 0.47 , and the mean number of neurologist visits was 0.28 (Table 2).

\section{Bivariate Analyses}

\section{Correlational Analyses Among Migraine Patients in the EU5}

There were weak, positive, and significant correlations among EU respondents between the number of HFDs and each of the following characteristics: employment status, marital status, household income, and level of education (all $p<0.05$; see Fig. 2). These results indicate that employed respondents had a greater number of HFDs than unemployed respondents, married respondents had a greater number of HFDs than respondents who were not married, and respondents with a university education had a greater number of HFDs than respondents who did not complete university education. Similarly, there were weak, positive, and significant correlations between the number of HFDs and CCI, BMI, alcohol use, and exercise in the past month (all $p<0.05$ ). These results indicate that respondents with more severe CCI and higher BMI had fewer HFDs than respondents with less severe CCI and respondents with lower BMI, respectively (data not shown). 
Table 1 Demographic characteristics of migraine patients with HFDs $(N=1569)$

\begin{tabular}{|c|c|}
\hline Parameters & $n(\%)$ \\
\hline \multicolumn{2}{|l|}{ Gender } \\
\hline Male & $349(22.2)$ \\
\hline Female & $1220(77.8)$ \\
\hline \multicolumn{2}{|l|}{ Country } \\
\hline France & $344(21.9)$ \\
\hline Germany & $409(26.1)$ \\
\hline United Kingdom & $375(23.9)$ \\
\hline Italy & $314(20.0)$ \\
\hline Spain & $127(8.1)$ \\
\hline \multicolumn{2}{|l|}{ Age group } \\
\hline $18-29$ & $309(19.7)$ \\
\hline $30-39$ & $343(21.9)$ \\
\hline $40-49$ & $393(25.0)$ \\
\hline $50-64$ & $389(24.8)$ \\
\hline $65+$ & $135(8.6)$ \\
\hline \multicolumn{2}{|l|}{ Marital status } \\
\hline Married or living with partner & $953(60.7)$ \\
\hline \multicolumn{2}{|l|}{ Household income } \\
\hline Low & $437(27.9)$ \\
\hline Medium & $577(36.8)$ \\
\hline High & $454(28.9)$ \\
\hline Declined to answer & $101(6.4)$ \\
\hline \multicolumn{2}{|l|}{ Level of education } \\
\hline Completed university education & $577(36.8)$ \\
\hline \multicolumn{2}{|l|}{ Employment status } \\
\hline Yes & $938(59.8)$ \\
\hline No & $631(40.2)$ \\
\hline \multicolumn{2}{|l|}{ CCI categories } \\
\hline 0 & $1136(72.4)$ \\
\hline 1 & $252(16.1)$ \\
\hline $2+$ & $181(11.5)$ \\
\hline
\end{tabular}

Table 1 continued

\begin{tabular}{ll}
\hline Parameters & $n$ (\%) \\
\hline BMI & $67(4.3)$ \\
Underweight $\left(<18.5 \mathrm{~kg} / \mathrm{m}^{2}\right)$ & $668(42.6)$ \\
Normal weight $\left(18.5\right.$ to $\left.<25.0 \mathrm{~kg} / \mathrm{m}^{2}\right)$ & $406(25.9)$ \\
Overweight $\left(25.0\right.$ to $\left.<30.0 \mathrm{~kg} / \mathrm{m}^{2}\right)$ & $360(22.9)$ \\
Obese $\left(30.0 \mathrm{~kg} / \mathrm{m}^{2}\right.$ and above) & $68(4.3)$ \\
Declined to answer & \\
Smoking status & $466(29.7)$ \\
Current & $413(26.3)$ \\
Former & $690(44.0)$ \\
Never & \\
Use of alcohol & $52(3.3)$ \\
Daily & $1074(68.5)$ \\
Less than daily & $443(28.2)$ \\
No & \\
Exercise in past 30 days & $945(60.2)$ \\
Yes & $624(39.8)$ \\
No & $43.27 \pm 13.81$ \\
Age in years $[$ mean $\pm S D]$ & $0.50 \pm 1.16$ \\
CCI [mean $\pm S D]$ &
\end{tabular}

$B M I$ body mass index, $C C I$ Charlson Comorbidity Index, $H F D$ s headache-free days, $S D$ standard deviation

\section{Multivariable Analyses}

Regression Analyses Among Migraine Patients in the EU5

Multivariable analyses were performed to examine the adjusted associations between the number of HFDs and outcomes after adjusting for the following covariates: sex, country, employment status, marital status, household income, education, BMI, alcohol use, exercise, age in years, and CCI. Based on multivariable GLMs, an increase of $1 \mathrm{HFD}$ was associated with average increases of 0.171 points for MCS, 0.306 points for PCS, 0.003 
Table 2 Health outcomes, WPAI, and HRU of migraine patients with HFDs

\begin{tabular}{|c|c|}
\hline Outcomes & $\begin{array}{l}\text { Mean } \pm \text { SD } \\
(N=1569)\end{array}$ \\
\hline \multicolumn{2}{|l|}{ HRQoL } \\
\hline MCS & $39.73 \pm 10.90$ \\
\hline PCS & $46.61 \pm 9.90$ \\
\hline SF-6D utility score & $0.62 \pm 0.12$ \\
\hline EQ-5D index & $0.71 \pm 0.26$ \\
\hline Health status, EQ VAS & $62.96 \pm 23.68$ \\
\hline \multicolumn{2}{|l|}{ WPAI } \\
\hline Absenteeism ${ }^{\mathrm{a}}$ & $13.39 \pm 26.05$ \\
\hline Presenteeism $^{a}$ & $34.70 \pm 27.84$ \\
\hline Total work productivity impairment ${ }^{a}$ & $37.73 \pm 30.17$ \\
\hline Activity impairment & $43.31 \pm 29.36$ \\
\hline \multicolumn{2}{|l|}{ HRU (in the past 6 months) } \\
\hline Total number of HCP visits & $8.38 \pm 9.29$ \\
\hline Total number of hospitalizations & $0.22 \pm 0.79$ \\
\hline Total number of ER visits & $0.47 \pm 1.25$ \\
\hline $\begin{array}{l}\text { Total number of general } \\
\text { practitioner/family practitioner visits }\end{array}$ & $3.02 \pm 3.65$ \\
\hline Total number of neurologist visits & $0.28 \pm 0.87$ \\
\hline Total number of psychiatrist visits & $0.36 \pm 1.79$ \\
\hline $\begin{array}{l}\text { Total number of psychologist/ } \\
\text { therapist visits }\end{array}$ & $0.87 \pm 3.65$ \\
\hline
\end{tabular}

$E R$ emergency room, EQ-5D EuroQoL-5D, EQ VAS EuroQol visual analog scale, $H C P$ healthcare provider, $H F D$ s headache-free days, $H R Q o L$ health-related quality of life, $H R U$ healthcare resource utilization, MCS mental component summary, PCS physical component summary, $S D$ standard deviation, $S F-6 D$ Short-Form Six-Dimension, $W P A I$ work productivity and activity impairment

a Includes employed respondents only; absenteeism $(n=877)$, presenteeism $(n=839)$, and total work productivity impairment $(n=832)$

points for SF-6D utility score, and 0.008 points for EQ-5D index score (all $p<0.001$ ). An increase of 5 HFDs would result in average increases of 0.855 points for MCS, 1.530 points for PCS, 0.015 points for SF-6D utility score, and 0.040 points for EQ-5D index score (Table 3 ).

An increase of 1 HFD was associated with expected decreases in absenteeism of $3.9 \%$, presenteeism and total work impairment of $2.1 \%$, and activity impairment of $1.8 \%$. An increase of 5 HFDs would result in expected decreases in absenteeism of $18.2 \%$, presenteeism of $10.3 \%$, total work impairment of $10.1 \%$, and activity impairment of $8.7 \%$ (Table 4).

Also, a greater number of HFDs was associated with fewer visits to different HCPs. An increase of 1 HFD was associated with expected decreases in HCP visits of $1.0 \%$ and neurologist visits of $4.7 \%$. Similarly, an increase of 5 HFDs would result in expected decreases in HCP visits of $4.7 \%$ and neurologist visits of $21.0 \%$, respectively (Table 5).

\section{DISCUSSION}

Previous studies have reported the relationship between migraine burden and patient-reported outcomes by comparing migraineurs with nonmigraine controls [16] or episodic with chronic migraineurs [12]. The present study adds to the existing knowledge by reporting, for the first time, associations between the number of HFDs and patient-reported outcomes in terms of HRQOL, WPAI, and HRU among migraine patients experiencing $\geq 4$ MHDs in the EU5.

The current study results are consistent with a recent study of migraine patients experiencing $\geq 4$ HFDs in the US, wherein 1 HFD was correlated with a 0.15 -point reduction in the Headache Impact Test (HIT)-6 score. Moreover, each 10-day increase in HFDs was associated with a 1.34-point reduction in HIT-6 score on average [19]. A corollary to Bell et al.'s study [19] was provided by a study by Vo et al. [16] wherein migraineurs suffering from $\geq 4$ MHDs reported a decreased QoL along with a reduced mean PCS, MCS, SF-6D health state utility score, and EQ-5D score compared to non-migraine controls in the EU5. Extrapolating the current study results to a tenfold increase in HFDs per month correlates with established minimally 


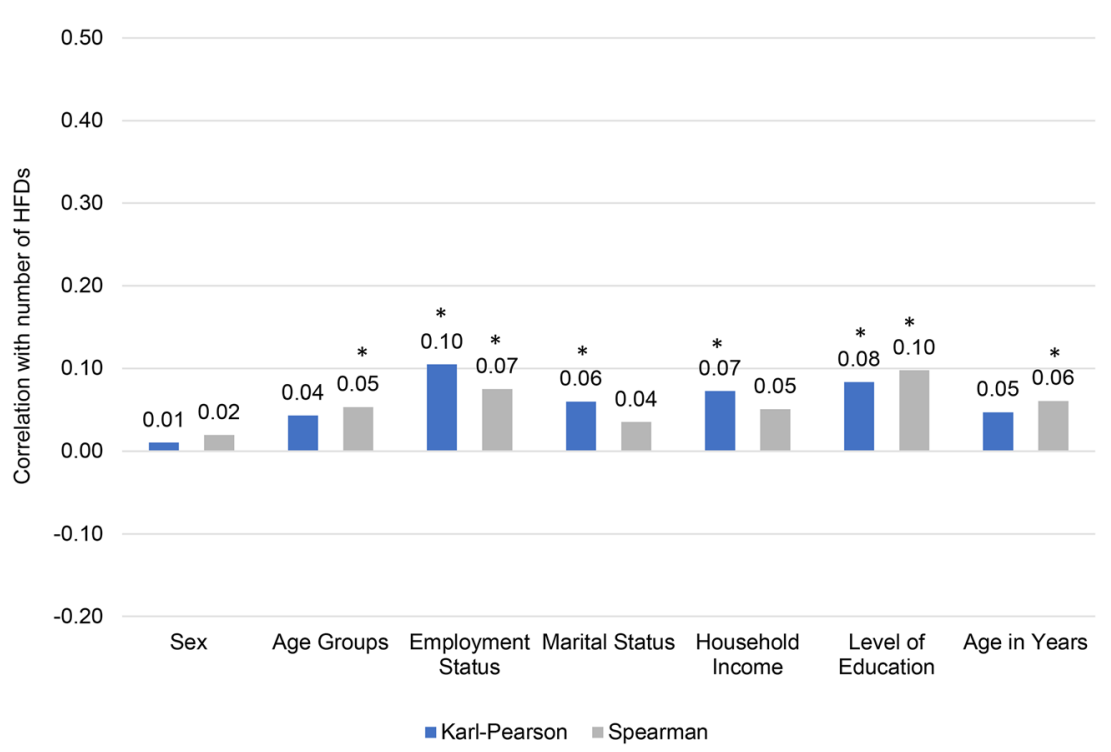

Fig. 2 Correlations between demographics and number of HFDs. HFDs headache-free days. ${ }^{*} p<0.05$. Variables are defined as: $\operatorname{sex}($ male $=1$, female $=0)$; age groups: $(18-29=1, \quad 30-39=2, \quad 40-49=3, \quad 50-64=4$, $65+=5$ ); employment status (yes $=1$, no $=0$ ); marital

important differences (MID) (for both MCS and PCS -3 points [21], SF-6D-0.041 points, and EQ-5D-0.074 points [28]), which would result in clinically meaningful increases in PCS and EQ-5D scores, thus increasing the QoL in migraine patients.

A systematic review of the literature identified physical functioning as one of the most important psychosocial difficulties encountered by migraine patients [29]. Existing evidence suggests an improvement in physical health with a consequent decrease in the frequency of headache days in migraine patients [30, 31]. EQ$5 \mathrm{D}$ provides a broader assessment of patients' health status [28], and the increased EQ-5D scores among migraine patients in our study could be related to the overall improved health status.

Previous studies have shown that increased migraine days result in greater work productivity loss, with higher levels of absenteeism and presenteeism, thereby imposing a greater economic burden on the individual, employer, and society [16, 32]. Migraineurs with 8 migraine days per month were predicted to have 0.95 absenteeism days and 2.34 presenteeism days status (married or living with partner $=1$, not married or living with partner $=0)$; household income (low $=1$, medium $=2$, high $=3$ ); level of education (completed university education $=1$, not completed university education $=0$ )

per month [33]. A study by Stewart et al. [34] reported that the mean lost productive time (the total of absenteeism and presenteeism) due to headaches was $4.7 \mathrm{~h}$ per week. In the present study, an increased number of HFDs was associated with less impairment of work activities among employed respondents after adjusting for covariates. The observed results are consistent with a previous study which showed that decreased levels of absenteeism and presenteeism in migraine patients were due to an increased number of HFDs [19].

Migraine imposes additional healthcare costs on the sufferers due to their increased use of healthcare resources [16, 35-37]. Previous research has shown that migraine patients make more visits to HCPs than non-migraine controls do $[16,38]$. Further, chronic migraineurs reported more visits to primary care physicians, neurologists, nurse practitioners, and other healthcare professionals than episodic migraineurs $[16,39]$. In the current study, an increase in the number of HFDs was associated with fewer visits to different HCPs.

Based on the results of the current study, it is evident that an increased number of HFDs is 
Table 3 Associations between HRQoL and HFDs according to regression analyses

\begin{tabular}{lllll}
\hline Outcomes & $\boldsymbol{B}$ & $\begin{array}{l}\mathbf{9 5 \%} \\
\text { confidence } \\
\text { interval }\end{array}$ & $\boldsymbol{p}$ value & $\begin{array}{l}\text { Estimated } \\
\text { increase } \\
\text { associated } \\
\text { with 5 } \\
\text { HFDs }\end{array}$ \\
\hline MCS & 0.171 & $0.095-0.247$ & $<0.001$ & 0.855 \\
PCS & 0.306 & $0.244-0.368$ & $<0.001$ & 1.530 \\
SF-6D & 0.003 & $0.003-0.004$ & $<0.001$ & 0.015 \\
utility & & & & \\
score & & & & \\
EQ-5D & 0.008 & $0.006-0.009$ & $<0.001$ & 0.040 \\
index & & & & \\
Health & 0.758 & $0.601-0.915$ & $<0.001$ & 3.790 \\
status, & & & & \\
EQ VAS & & & & \\
\hline
\end{tabular}

Generalized linear regression models with a normal distribution were used to adjust for covariates. Covariates $=\operatorname{sex} \quad($ female $=$ reference $), \quad$ country $\quad(\mathrm{UK}=$ reference), BMI (normal weight $=$ reference), employment status (employed $=$ reference), marital status (not married $=$ reference $)$, household income $($ low $=$ reference $)$, education (not completed university $=$ reference), alcohol $($ none $=$ reference $)$ exercise $($ no $=$ reference $)$, age $($ years $)$, and CCI

EQ-5D EuroQoL-5D, EQ VAS EuroQol visual analog scale, $H F D s$ headache-free days, $H R Q o L$ health-related quality of life, $M C S$ mental component summary, $P C S$ physical component summary, SF-6D Short-Form SixDimension

associated with increased work productivity and reduced HRU, which are in turn expected to result in lower indirect and direct costs. A study of migraine patients in the US showed that increasing the number of HFDs from 0-10 to 21-26 per month had a greater impact on indirect costs than on direct costs [19]. Therefore, increasing the number of HFDs may reduce annual costs for patients suffering from migraine.

The aim of any prophylactic treatment is to reduce disability and to restore functional ability by decreasing the frequency and severity of migraine $[7,40]$. Studies on preventive pharmacologic treatment in migraine patients have shown that decreasing the frequency of migraine and the number of headache days significantly improves measures of migraine disability, impact of migraine, HRQoL [41], absenteeism and presenteeism [42], HRU, and costs [43]. In a study by Santoro et al. [44], medications significantly reduced MHDs compared to baseline and also reduced the intensity from Migraine Disability Assessment Scale (MIDAS) grade IV from the sixth month of treatment in patients with chronic migraine. Recent studies have reported clinically relevant improvements in patient-reported outcomes after treatment with erenumab in chronic migraine patients $[41,42]$. Based on the results available, we propose that decreasing the frequency of migraine is an important determinant of improvements in QoL and other measures; hence, physicians treating migraine patients should consider reducing MHDs or increasing the number of HFDs. Future studies targeting an increase in the frequency of HFDs with appropriate therapeutic regimens that may translate to improved QoL or potential cost savings are necessary.

\section{Limitations}

This study has a few limitations. The NHWS is a panel-based survey, and though the panel administrators attempted to have the panel mirror the population as closely as possible (i.e., age and gender quotas for NHWS sampling), there could be a bias in the estimates whereby there are differences between the population in each country and the panel population. This would be most likely among segments of the population that do not have ready access to the 
Table 4 Associations between WPAI and HFDs according to regression analyses

\begin{tabular}{|c|c|c|c|c|c|c|c|c|}
\hline \multirow[t]{2}{*}{ Outcomes } & \multirow[t]{2}{*}{$B$} & \multirow[t]{2}{*}{$\begin{array}{l}95 \% \\
\text { confidence } \\
\text { interval }\end{array}$} & \multirow[t]{2}{*}{$p$ value } & \multirow[t]{2}{*}{$\begin{array}{l}\text { Rate } \\
\text { ratio } \\
\text { (RR) }\end{array}$} & \multicolumn{2}{|c|}{$\begin{array}{l}95 \% \text { Wald } \\
\text { confidence } \\
\text { interval for } \\
\text { RR }\end{array}$} & \multirow[t]{2}{*}{$\begin{array}{l}\% \\
\text { decrease }^{a}\end{array}$} & \multirow[t]{2}{*}{$\begin{array}{l}\text { Estimated reduction } \\
\text { associated with } 5 \text { HFDs }\end{array}$} \\
\hline & & & & & Lower & Upper & & \\
\hline Absenteeism & -0.040 & $\begin{array}{c}-0.051 \text { to } \\
-0.029\end{array}$ & $<0.001$ & 0.961 & 0.950 & 0.971 & 3.94 & 0.182 \\
\hline Presenteeism & -0.022 & $\begin{array}{c}-0.033 \text { to } \\
-0.010\end{array}$ & $<0.001$ & 0.979 & 0.968 & 0.990 & 2.14 & 0.103 \\
\hline $\begin{array}{l}\text { Total work } \\
\text { productivity }\end{array}$ & -0.021 & $\begin{array}{c}-0.033 \text { to } \\
-0.010\end{array}$ & $<0.001$ & 0.979 & 0.968 & 0.990 & 2.10 & 0.101 \\
\hline $\begin{array}{l}\text { Activity } \\
\text { impairment }\end{array}$ & -0.018 & $\begin{array}{c}-0.026 \text { to } \\
-0.011\end{array}$ & $<0.001$ & 0.982 & 0.975 & 0.989 & 1.79 & 0.087 \\
\hline
\end{tabular}

Generalized linear regression models with a negative binomial distribution were used to adjust for covariates. Employed $N=938$. Absenteeism, presenteeism, and total work productivity among employed respondents only. Covariates $=$ sex $($ female $=$ reference $)$, country $(\mathrm{UK}=$ reference $), \mathrm{BMI}($ normal weight $=$ reference $)$, employment status $($ employed $=$ reference; only for activity impairment), marital status (not married $=$ reference), household income (low $=$ reference), education (not completed university $=$ reference), alcohol $($ none $=$ reference), exercise $($ no $=$ reference), age (years), and CCI

HFDs headache-free days, WPAI work productivity and activity impairment

${ }^{a} \mathrm{RR}<1$ is associated with a $(1-\mathrm{RR}) \times 100 \%$ decrease in WPAI outcomes per increase of $1 \mathrm{HFD}$. RR $>1$ is associated with a $(1+\mathrm{RR}) \times 100 \%$ increase in WPAI outcomes per increase of $1 \mathrm{HFD}$

internet (e.g., elderly people, institutionalized patients, and those with severe comorbidities and disabilities).

Another limitation is the use of self-reported data, since the diagnosis of migraine and other relevant diagnoses (e.g., those used to calculate the CCI) cannot be confirmed; nor can reports of healthcare visits.

The magnitude of the impact of migraine is likely affected by the frequency, severity, and duration of migraine. Moderate or severe pain is one of the diagnostic criteria for migraine, and available data on measures of severity are likely to be too coarse to be useful given this range restriction, so severity is not considered here. Duration is not captured in the NHWS, except for an item to confirm the 4-h to 72-h duration included in the diagnostic criteria, and so duration may be an important unmeasured variable in this study.

\section{CONCLUSION}

Previous studies have shown worsened HRQoL and greater work productivity loss and HRU in migraine patients. This study provides the first evidence that an increase in the number of HFDs is associated with improved HRQoL, decreased work productivity loss and activity impairment, and HRU among patients with migraine in the EU5. Thus, increasing the frequency of HFDs using appropriate medications may lessen the burden of migraine and 
Table 5 Associations between HRU and HFDs according to regression analyses

\begin{tabular}{|c|c|c|c|c|c|c|c|c|}
\hline \multirow[t]{2}{*}{ Outcomes } & \multirow[t]{2}{*}{$B$} & \multirow[t]{2}{*}{$\begin{array}{l}95 \% \\
\text { confidence } \\
\text { interval }\end{array}$} & \multirow[t]{2}{*}{$p$ value } & \multirow[t]{2}{*}{$\begin{array}{l}\text { Rate } \\
\text { ratio } \\
(\mathbf{R R})\end{array}$} & \multicolumn{2}{|c|}{$\begin{array}{l}95 \% \text { Wald } \\
\text { confidence } \\
\text { interval for } \\
\text { RR }\end{array}$} & \multirow[t]{2}{*}{$\begin{array}{l}\% \\
\text { decrease }^{a}\end{array}$} & \multirow[t]{2}{*}{$\begin{array}{l}\text { Estimated } \\
\text { reduction } \\
\text { associated } \\
\text { with } 5 \text { HFDs }\end{array}$} \\
\hline & & & & & Lower & Upper & & \\
\hline $\begin{array}{l}\text { Total number of HCP visits in } \\
\text { the past } 6 \text { months }\end{array}$ & -0.010 & $\begin{array}{c}-0.017 \text { to } \\
-0.002\end{array}$ & 0.015 & 0.990 & 0.983 & 0.998 & 0.96 & 0.047 \\
\hline $\begin{array}{l}\text { Total number of } \\
\text { hospitalizations in the past } \\
6 \text { months }\end{array}$ & -0.023 & $\begin{array}{l}-0.039 \text { to } \\
-0.007\end{array}$ & 0.005 & 0.978 & 0.962 & 0.993 & 2.24 & 0.107 \\
\hline $\begin{array}{l}\text { Total number of ER visits in } \\
\text { the past } 6 \text { months }\end{array}$ & -0.020 & $\begin{array}{c}-0.033 \text { to } \\
-0.007\end{array}$ & 0.002 & 0.980 & 0.968 & 0.993 & 1.99 & 0.096 \\
\hline $\begin{array}{l}\text { Total number of general } \\
\text { practitioner/family } \\
\text { practitioner visits in the past } \\
6 \text { months }\end{array}$ & -0.014 & $\begin{array}{c}-0.023 \text { to } \\
-0.006\end{array}$ & 0.001 & 0.986 & 0.977 & 0.994 & 1.43 & 0.069 \\
\hline $\begin{array}{l}\text { Total number of neurologist } \\
\text { visits in the past } 6 \text { months }\end{array}$ & -0.047 & $\begin{array}{c}-0.062 \text { to } \\
-0.032\end{array}$ & $<0.001$ & 0.954 & 0.940 & 0.968 & 4.70 & 0.210 \\
\hline $\begin{array}{l}\text { Total number of psychiatrist } \\
\text { visits in the past } 6 \text { months }\end{array}$ & -0.010 & $\begin{array}{c}-0.025 \text { to } \\
0.005\end{array}$ & 0.204 & 0.990 & 0.976 & 1.005 & 0.96 & 0.047 \\
\hline $\begin{array}{l}\text { Total number of psychologist/ } \\
\text { therapist visits in the past } \\
6 \text { months }\end{array}$ & -0.007 & $\begin{array}{c}-0.019 \text { to } \\
0.004\end{array}$ & 0.213 & 0.993 & 0.981 & 1.004 & 0.73 & 0.036 \\
\hline
\end{tabular}

Generalized linear regression models with a negative binomial distribution were used to adjust for covariates. Covariates $=\operatorname{sex}($ female $=$ reference $)$, country $(\mathrm{UK}=$ reference $), B M I$ (normal weight $=$ reference $)$, employment status $($ employed $=$ reference), marital status (not married $=$ reference), household income (low = reference), education (not completed university $=$ reference), alcohol $($ none $=$ reference $)$, exercise $($ no $=$ reference $)$, age $($ years $)$, and CCI

$E R$ emergency room, HCP healthcare provider, HFDs headache-free days, $H R U$ healthcare resource utilization

a $\mathrm{RR}<1$ is associated with a $(1-\mathrm{RR}) \times 100 \%$ decrease of HRU outcomes per increase of $1 \mathrm{HFD}$. RR $>1$ is associated with $(1+\mathrm{RR}) \times 100 \%$ increase of HRU outcomes per increase of $1 \mathrm{HFD}$

provide incremental benefits to individuals and society.

\section{ACKNOWLEDGEMENTS}

The authors thank the participants in the study.

Funding. Sponsorship for this study and the Rapid Service Fee were funded by Novartis Pharma AG, Switzerland. Kantar Health conducted the NHWS and received funding to analyze and develop the manuscript from Novartis. All authors had full access to all of the data in this study and take complete responsibility for the integrity of the data and accuracy of the data analysis.

Medical Writing and Editorial Assistance. The authors acknowledge Kamalakkannan Naidu, PhD and Ramu Periyasamy, PhD of Indegene Pvt Ltd. for assistance with the literature review and with the writing of the 
manuscript. Funding for this assistance was provided by Kantar Health.

Authorship. All named authors meet the International Committee of Medical Journal Editors (ICMJE) criteria for authorship for this article, take responsibility for the integrity of the work as a whole, and have given their approval for this version to be published.

Authorship Contributions. MJD, SG, PV, AKL, and JF conceived and designed the study. MJD and SG analyzed the data. MJD, SG, PV, $\mathrm{AKL}$, and JF interpreted the results and helped write the paper.

Disclosures. Shaloo Gupta is an employee of Kantar Health. Michael J. Doane was an employee of Kantar Health at the time the study was conducted and is now an employee of Alkermes, Inc. Pamela $\mathrm{Vo}$ is an employee of Novartis, which funded the current study. Juanzhi Fang is an employee of Novartis, which funded the current study. Annik K. Laflamme is an employee of Novartis, which funded the current study.

Compliance with Ethics Guidelines. The protocol and questionnaire for the NHWS were reviewed by the Pearl Institutional Review Board and exempted from review for the current study. All NHWS respondents provided informed consent prior to their participation.

Data Availability. The NHWS data used in this study are available for noncommercial research and validation purposes upon request. Interested individuals may access these data for the purposes above in the same manner as the authors did without any additional restrictions. Interested parties should contact the corresponding author on reasonable request.

Open Access. This article is distributed under the terms of the Creative Commons Attribution-NonCommercial 4.0 International License (http://creativecommons.org/licenses/ by-nc/4.0/), which permits any noncommercial use, distribution, and reproduction in any medium, provided you give appropriate credit to the original author(s) and the source, provide a link to the Creative Commons license, and indicate if changes were made.

\section{REFERENCES}

1. World Health Organization. Headache disorders. 2016. https://www.who.int/news-room/fact-sheets/ detail/headache-disorders. Accessed 4 Oct 2018.

2. Ahmed F. Headache disorders: differentiating and managing the common subtypes. $\mathrm{Br} \mathrm{J}$ Pain. 2012;6(3):124-32.

3. Headache Classification Committee of the International Headache Society (IHS). The International Classification of Headache Disorders, 3rd edition. Cephalalgia. 2018;38(1):1-211.

4. GBD 2016 Disease and Injury Incidence and Prevalence Collaborators. Global, regional, and national incidence, prevalence, and years lived with disability for 328 diseases and injuries for 195 countries, 1990-2016: a systematic analysis for the Global Burden of Disease Study 2016. Lancet. 2017;390:1211-59.

5. Woldeamanuel YW, Cowan RP. Migraine affects 1 in 10 people worldwide featuring recent rise: a systematic review and meta-analysis of communitybased studies involving 6 million participants. J Neurol Sci. 2017;372:307-15.

6. Becker C, Brobert GP, Almqvist PM, Johansson S, Jick SS, Meier CR. Migraine incidence, comorbidity and health resource utilization in the UK. Cephalalgia. 2008;28:57-64.

7. Lipton RB, Bigal ME, Diamond M, Freitag F, Reed ML, Stewart WF. Migraine prevalence, disease burden, and the need for preventive therapy. Neurology. 2007;68:343-9.

8. Buse DC, Rupnow MFT, Lipton RB. Assessing and managing all aspects of migraine: migraine attacks, migraine-related functional impairment, common comorbidities, and quality of life. Mayo Clin Proc. 2009;84(5):422-35.

9. Lantéri-Minet M, Duru G, Mudge M, Cottrell S. Quality of life impairment, disability and economic burden associated with chronic daily headache, focusing on chronic migraine with or without medication overuse: a systematic review. Cephalalgia. 2011;31(7):837-50. 
10. Mennini FS, Gitto L, Martelletti P. Improving care through health economics analyses: cost of illness and headache. J Headache Pain. 2008;9:199-206.

11. Stovner LJ, Andrée C. Impact of headache in Europe: a review for the Eurolight project. J Headache Pain. 2008;9:139-46.

12. Blumenfeld AM, Varon SF, Wilcox TK, Buse DC, Kawata AK, Manack A, et al. Disability, HRQoL and resource use among chronic and episodic migraineurs: results from the International Burden of Migraine Study (IBMS). Cephalalgia. 2011;31(3):301-15.

13. Stewart WF, Wood GC, Manack A, Varon SF, Buse DC, Lipton RB. Employment and work impact of chronic migraine and episodic migraine. J Occup Environ Med. 2010;52(1):8-14.

14. Lipton RB, Buse DC, Saiers J, Serrano D, Reed ML. Healthcare resource utilization and direct costs associated with frequent nausea in episodic migraine: results from the American Migraine Prevalence and Prevention (AMPP) Study. J Med Econ. 2013;16(4):490-9.

15. Diener HC, Solbach K, Holle D, Gaul C. Integrated care for chronic migraine patients: epidemiology, burden, diagnosis and treatment options. Clin Med. 2015;15(4):344-50.

16. Vo P, Fang J, Bilitou A, Laflamme AK, Gupta S. Patients' perspective on the burden of migraine in Europe: a cross-sectional analysis of survey data in France, Germany, Italy, Spain, and the United Kingdom. J Headache Pain. 2018;19:82.

17. Weatherall MW. The diagnosis and treatment of chronic migraine. Ther Adv Chronic Dis. 2015;6(3):115-23.

18. Lipton RB, Silberstein SD. Episodic and chronic migraine headache: breaking down barriers to optimal treatment and prevention. Headache. 2015;55(suppl 2):103-22.

19. Bell J, Lee L, Fitzgerald T, Cohen JM. The impact of headache free days on quality of life and costs among people with migraine with $\geq 4$ headache days in the past month. Neurology. 2018;90(suppl 15):P3.139.

20. Charlson ME, Pompei P, Ales KL, MacKenzie CR. A new method of classifying prognostic comorbidity in longitudinal studies: development and validation. J Chronic Dis. 1987;40(5):373-83.

21. Maruish ME, editor. User's manual for the SF-36v2 Health Survey. 3rd ed. Lincoln: QualityMetric Incorporated; 2011.
22. Brazier J, Roberts J, Deverill M. The estimation of a preference-based measure of health from the SF-36. J Health Econ. 2002;21(2):271-92.

23. Herdman M, Gudex C, Lloyd A, Janssen M, Kind P, Parkin D, et al. Development and preliminary testing of the new five-level version of EQ-5D (EQ-5D5L). Qual Life Res. 2011;20(10):1727-36.

24. Reilly MC, Zbrozek AS, Dukes EM. The validity and reproducibility of a work productivity and activity impairment instrument. Pharmacoeconomics. 1993;4(5):353-65.

25. Gupta S, Goren A, Phillips AL, Stewart M. Self-reported burden among caregivers of patients with multiple sclerosis. Int J MS Care. 2012;14:179-87.

26. DiBonaventura M, Gupta S, McDonald M, Sadosky A. Evaluating the health and economic impact of osteoarthritis pain in the workforce: results from the National Health and Wellness Survey. BMC Musculoskelet Disord. 2011;12:83.

27. Goren A, Liu X, Gupta S, Simon TA, Phatak H. Quality of life, activity impairment, and healthcare resource utilization associated with atrial fibrillation in the US National Health and Wellness Survey. PLoS One. 2013;8(8):e71264.

28. Walters SJ, Brazier JE. Comparison of the minimally important difference for two health state utility measures: EQ-5D and SF-6D. Qual Life Res. 2005;14(6):1523-32.

29. Raggi A, Giovannetti AM, Quintas R, D'Amico D, Cieza A, Sabariego C, et al. A systematic review of the psychosocial difficulties relevant to patients with migraine. J Headache Pain. 2012;13:595-606.

30. Bordini CA, da Silva HM, Garbelini RP, Teixeira SO, Speciali JG. Effect of preventive treatment on health-related quality of life in episodic migraine. J Headache Pain. 2005;6:387-91.

31. Brandes JL, Kudrow DB, Rothrock JF, Rupnow MFT, Fairclough DL, Greenberg SJ. Assessing the ability of topiramate to improve the daily activities of patients with migraine. Mayo Clin Proc. 2006;81(10):1311-9.

32. Steiner TJ, Stovner LJ, Katsarava Z, Lainez JM, Lampl C, Lantéri-Minet $M$. The impact of headache in Europe: principal results of the Eurolight project. J Headache Pain. 2014;15:31.

33. Porter JK, Di Tanna GL, Lipton RB, Sapra S, Villa G. Costs of acute headache medication use and productivity losses among patients with migraine: insights from three randomized controlled trials. Pharmacoecon Open. 2018. https://doi.org/10. 1007/s41669-018-0105-0. 
34. Stewart WF, Wood GC, Razzaghi H, Reed ML, Lipton RB. Work impact of migraine headaches. J Occup Environ Med. 2008;50:736-45.

35. Stokes M, Becker WJ, Lipton RB, Sullivan SD, Wilcox TK, Wells L, et al. Cost of health care among patients with chronic and episodic migraine in Canada and the USA: results from the International Burden of Migraine Study (IBMS). Headache. 2011;51:1058-77.

36. Bloudek LM, Stokes M, Buse DC, Wilcox TK, Lipton RB, Goadsby PJ, et al. Cost of healthcare for patients with migraine in five European countries: results from the International Burden of Migraine Study (IBMS). J Headache Pain. 2012;13:361-78.

37. Linde M, Gustavsson A, Stovner LJ, Steiner TJ, Barre J, Katsarava Z, et al. The cost of headache disorders in Europe: the Eurolight project. Eur J Neurol. 2012;19:703-11.

38. Silberstein SD, Lee L, Gandhi K, Fitzgerald T, Bell J, Cohen JM. Health care resource utilization and migraine disability along the migraine continuum among patients treated for migraine. Headache. 2018;58:1579-92.

39. Messali A, Sanderson JC, Blumenfeld AM, Goadsby PJ, Buse DC, Varon SF, et al. Direct and indirect costs of chronic and episodic migraine in the
United States: a web-based survey. Headache. 2016;56:306-22.

40. Antonaci F, Ghiotto N, Wu S, Pucci E, Costa A. Recent advances in migraine therapy. Springerplus. 2016;5:637.

41. Buse DC, Lipton RB, Hallström Y, Reuter U, Tepper SJ, Zhang F, et al. Migraine-related disability, impact, and health-related quality of life among patients with episodic migraine receiving preventive treatment with erenumab. Cephalalgia. 2018;38:1622-31.

42. Lipton RB, Tepper SJ, Reuter U, Silberstein S, Stewart WF, Nilsen $J$, et al. Erenumab in chronic migraine: patient-reported outcomes in a randomized double-blind study. Neurology. 2019;92:e2250-60.

43. Freitag FG, Lyss H, Nissan GR. Migraine disability, healthcare utilization, and expenditures following treatment in a tertiary headache center. Proc (Bayl Univ Med Cent). 2013;26:363-7.

44. Santoro A, Fontana A, Miscio AM, Zarrelli MM, Copetti M, Leone MA. Quarterly repeat cycles of onabotulinumtoxinA in chronic migraine patients: the benefits of the prolonged treatment on the continuous responders and quality-of-life conversion rate in a real-life setting. Neurol Sci. 2017;38:1779-89. 